\title{
Endoscopic treatment of chronic pancreatitis: European Society of Gastrointestinal Endoscopy (ESGE) Clinical Guideline
}

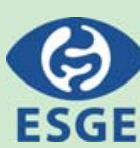

Authors

Institutions
J.-M. Dumonceau' ${ }^{1}$, M. Delhaye ${ }^{2}$, A. Tringali ${ }^{3}$, J. E. Dominguez-Munoz ${ }^{4}$, J.-W. Poley ${ }^{5}$, M. Arvanitaki ${ }^{2}$, G. Costamagna ${ }^{3}$, F. Costea ${ }^{6}$, J. Devière ${ }^{2}$, P. Eisendrath ${ }^{7}$, S. Lakhtakia ${ }^{8}$, N. Reddy ${ }^{8}$, P. Fockens ${ }^{9}$, T. Ponchon ${ }^{10}$, M. Bruno ${ }^{5}$

Institutions are listed at the end of article. submitted 14. March 2012 accepted 20. March 2012

\section{Bibliography}

DOI http://dx.doi.org/

$10.1055 / \mathrm{s}-0032-1309840$

Published online: 2.7 .2012

Endoscopy 2012; 44: 784-796

(c) Georg Thieme Verlag KG

Stuttgart · New York

ISSN 0013-726X

\section{Corresponding author} J.-M. Dumonceau, MD PhD

Division of Gastroenterology and Hepatology

Geneva University Hospitals

Rue Gabrielle Perret Gentil 4

1211 Geneva

Switzerland

Fax: + 41-22-3729366

jmdumonceau@hotmail.com
Background and aims: Clarification of the position of the European Society of Gastrointestinal Endoscopy (ESGE) regarding the interventional options available for treating patients with chronic pancreatitis.

Methods: Systematic literature search to answer explicit key questions with levels of evidence serving to determine recommendation grades. The ESGE funded development of the Guideline.

Summary of selected recommendations

For treating painful uncomplicated chronic pancreatitis, the ESGE recommends extracorporeal shockwave lithotripsy/endoscopic retrograde cholangiopancreatography as the first-line interventional option. The clinical response should be evaluated at 6-8 weeks; if it appears unsatisfactory, the patient's case should be discussed again in a multidisciplinary team. Surgical options should be considered, in particular in patients with a predicted poor outcome following endoscopic therapy (Recommendation grade B). For treating chronic pancreatitis associated with radiopaque stones $\geq 5 \mathrm{~mm}$ that obstruct the main pancreatic duct, the ESGE recommends extracorporeal shockwave lithotripsy as a first step, combined or not with endoscopic extraction of stone

\section{Introduction}

$\nabla$

Endoscopic therapy of chronic pancreatitis aims at relieving pain. Pain is generally considered to be multifactorial, caused by pancreatic neural remodeling and neuropathy, increased intraductal and parenchymal pressure, pancreatic ischemia and acute inflammation during an acute relapse. Complications such as pseudocysts, strictures of the common bile duct (CBD) and pancreatic cancer may also cause pancreatic-type pain. Most nonsurgical interventions for pain in patients with chronic pancreatitis who do not present these complications (with "uncomplicated chronic pancreatitis") aim at relieving outflow obstruc- fragments depending on the expertise of the center (Recommendation grade B).

For treating chronic pancreatitis associated with a dominant stricture of the main pancreatic duct, the ESGE recommends inserting a single 10-Fr plastic stent, with stent exchange planned within 1 year (Recommendation grade $\mathrm{C}$ ). In patients with ductal strictures persisting after 12 months of single plastic stenting, the ESGE recommends that available options (e.g., endoscopic placement of multiple pancreatic stents, surgery) be discussed in a multidisciplinary team (Recommendation grade D).

For treating uncomplicated chronic pancreatic pseudocysts that are within endoscopic reach, the ESGE recommends endoscopic drainage as a first-line therapy (Recommendation grade A).

For treating chronic pancreatitis-related biliary strictures, the choice between endoscopic and surgical therapy should rely on local expertise, patient co-morbidities and expected patient compliance with repeat endoscopic procedures (Recommendation grade D). If endoscopy is elected, the ESGE recommends temporary placement of multiple, side-by-side, plastic biliary stents (Recommendation grade $\mathrm{A}$ ).

tion of the main pancreatic duct (MPD). In a large multicenter study of endoscopic therapy in chronic pancreatitis, MPD obstruction was caused by strictures ( $47 \%$ ), stones (18\%) or a combination of both (32\%) [1]. Drainage of pseudocysts and treatment of CBD strictures were performed in $17 \%$ and $23 \%$ of patients, respectively.

This Guideline on endoscopic treatment in chronic pancreatitis has been endorsed by the European Society for Gastrointestinal Endoscopy (ESGE). A quick reference guide summarizing its recommendations is available online (Appendix e1). 


\section{Methods}

The European Society of Gastrointestinal Endoscopy (ESGE) commissioned and funded this Guideline. The methodology, including assessment of evidence levels and recommendation grades, was similar to that used for other ESGE Guidelines [2]. Briefly, subgroups were formed, each charged with a series of clearly defined key questions (see Appendix e2, available online). The committee chair worked with subgroup leaders to identify pertinent search terms that always included "chronic pancreatitis" and words pertinent to specific key questions. Evidence tables were generated for each key question based on the best available evidence (see Appendix e3, available online). Subgroups agreed by online communication on draft proposals that were presented to the entire group for general discussion during a meeting held in Brussels in May 2011. The results of that discussion were incorporated into the subsequent Guideline draft version and again discussed using online communication until unanimous agreement was reached. Searches were re-run in June 2011 (this date should be taken into account for future updates). All members of the Guideline development group approved the final draft; it was peer-reviewed and, after modifications, sent to all individual ESGE members in February 2012 for their comments. The final guideline was endorsed by the ESGE Governing Board.

Evidence statements and recommendations are shown in italics for easier reference; key evidence statements and recommendations are in bold. This Guideline will be considered for revision in 2015 , or sooner if important new evidence becomes available (any interim updates will be noted on the ESGE website: http:// www.esge.com/esge-guidelines.html).

\section{Initial work-up and choice of treatment}

$\nabla$

Computed tomography $(C T)$ scanning is the most sensitive and accurate noninvasive method to identify pancreatic calcifications (Evidence level 2+). Magnetic resonance with cholangiopancreatography (MRCP) is the best noninvasive technique to assess the anatomy of the biliary tree (Evidence level $2++$ ), of the pancreatic ducts, and of post-necrotic pancreatic fluid collections (Evidence level $2+$ ).

The ESGE recommends performing CT scanning to plan treatment of chronic pancreatitis (Recommendation C). A combination of other imaging modalities (e.g., MRCP or endoscopic ultrasonography [EUS] plus CT scanning or abdominal X-ray) may be preferable in specific circumstances (e.g., suspected anatomical variants of the pancreatic ducts, CBD strictures, or drainage of post-necrotic pancreatic fluid collections) (Evidence level B).

CT scanning allows detection of pancreatic calcifications and broad assessment of the pancreatic parenchyma. The anatomy of pancreatic ducts, including MPD strictures and anatomical variants (e.g., pancreas divisum), is best assessed using MRCP $[3,4]$, including intravenous injection of secretin in selected cases [5].

For the work-up of pancreatic fluid collections, a prospective comparative study concluded that magnetic resonance imaging (MRI) was superior to CT scanning because it depicts solid necrotic debris that may impede effective drainage [6]. EUS provides similar information. These imaging modalities have not been compared for the detection of pseudoaneurysms close to pseudocysts, which is another potentially important consideration when planning treatment.
Chronic pancreatitis is associated with an increased risk of pancreatic cancer. The differential diagnosis of chronic pancreatitis vs. pancreatic cancer may be challenging (Evidence level 1+). In patients with a pancreatic mass or an MPD or CBD stricture in the context of chronic pancreatitis, an adequate work-up should be performed to reasonably rule out a pancreatic cancer (Recommendation grade A). Special attention to the possibility of concurrent pancreatic cancer should be paid in patients $>50$ years, of female gender, of white race, presenting with jaundice, in the absence of pancreatic calcifications, or in the presence of exocrine insufficiency, as well as in patients with hereditary pancreatitis [7-9]. The accuracy of standard CT scanning for the detection of pancreatic cancer is limited in the context of chronic pancreatitis [10,11]. Triplephase CT scanning with time-attenuation curves has yielded $90 \%$ accuracy for differentiating chronic pancreatitis from pancreatic cancer; this examination has been recommended as a first-choice procedure in an evidence-based algorithm for the work-up of mass lesions in chronic pancreatitis, followed by MRCP, EUS-FNA and positron emission tomography (PET)-CT $[12,13]$. With EUS, the differentiation between pancreatic cancer and focal pancreatitis is difficult (accuracy < 75\%) $[14,15]$; adding EUS-guided sampling to EUS significantly improved the diagnostic yield in one retrospective study [14]. Interestingly, in three retrospective studies involving 1131 patients in total, the negative predictive value of EUS-guided sampling for pancreatic cancer was higher in the presence vs. in the absence of chronic pancreatitis (89-94\% vs. $45-93 \%$ ) $[8,16,17]$. If EUS-guided sampling is inconclusive, repeat EUS-guided sampling with rapid on-site cytopathological examination, PET-CT, or surgical resection are recommended $[13,18]$. If a CBD stricture is treated by ERCP in the context of chronic pancreatitis, adequate biliary sampling should be obtained before stent insertion $[19,20]$. Other diseases that may be difficult to differentiate from chronic pancreatitis include autoimmune pancreatitis and intraductal papillary mucinous neoplasm. For the diagnosis of these diseases, the reader is referred to recent guidelines [18,21,22]. In this regard, demographic data may also prove helpful because, compared with patients with chronic pancreatitis, those with intraductal papillary mucinous neoplasm are significantly more often females, are older, drink less alcohol, and smoke fewer cigarettes [23].

The choice between surgical and endoscopic therapy in patients with painful uncomplicated chronic pancreatitis may be influenced by the following considerations: (i) two randomized controlled trials (RCTs) have shown better pain control following surgery compared with endoscopic therapy; (ii) endoscopic therapy does not preclude surgical treatment of chronic pancreatitis and it is safer; (iii) predictors of satisfactory outcome following endoscopic therapy have been identified (Evidence level 1+).

The ESGE recommends endoscopic therapy as the first-line therapy for painful uncomplicated chronic pancreatitis. The clinical response should be evaluated at 6-8 weeks; if it appears unsatisfactory, the patient's case should be discussed again in a multidisciplinary team with endoscopists, surgeons, and radiologists and surgical options should be considered, in particular in patients with a predicted poor outcome following endoscopic therapy (Recommendation grade B). The RCTs that have compared interventions for the treatment of painful uncomplicated chronic pancreatitis are summarized in - Table 1. In the first RCT comparing endoscopic therapy vs. surgery [24], pain was absent after 5 years of follow-up in $15 \%$ vs. $34 \%$ of endoscopic therapy vs. surgery patients, respectively, showing that neither of these options is entirely satisfactory. In 


\begin{tabular}{|c|c|c|c|c|c|c|}
\hline & \multicolumn{2}{|c|}{$\begin{array}{l}\text { Dite et al., } 2003 \text { [24] } \\
\text { (Follow-up, } 5 \text { years) }\end{array}$} & \multicolumn{2}{|c|}{$\begin{array}{l}\text { Cahen et al., } 2007[25,26] \\
\text { (Follow-up, } 6 \text { years) }\end{array}$} & \multicolumn{2}{|c|}{$\begin{array}{l}\text { Dumonceau et al., } 2007 \text { [34] } \\
\text { (Follow-up, } 4 \text { years) }\end{array}$} \\
\hline & ERCP & Surgery & $E S W L+E R C P$ & $\begin{array}{l}\text { Surgical pancrea- } \\
\text { tico-jejunostomy }\end{array}$ & ESWL & $E S W L+E R C P$ \\
\hline $\mathrm{n}$ & 36 & 36 & 19 & 20 & 26 & 29 \\
\hline \multicolumn{7}{|l|}{ Pain relief, \% } \\
\hline Complete & 15 & $34^{1}$ & 16 & $40^{1}$ & 58 & 55 \\
\hline Partial & 46 & 52 & 16 & 35 & n.d. & n.d. \\
\hline
\end{tabular}

ERCP, endoscopic retrograde cholangiopancreatography; ESWL, extracorporeal shockwave lithotripsy; n.d., no data. $1 P<0.05$.

Table 2 Long-term outcome after endoscopic treatment of chronic pancreatitis.

\begin{tabular}{|c|c|c|c|c|c|}
\hline First author, year & $\mathbf{n}$ & Follow-up, months & Surgery & $\begin{array}{l}\text { Ongoing endoscopic } \\
\text { treatment }\end{array}$ & $\begin{array}{l}\text { No further } \\
\text { intervention }\end{array}$ \\
\hline Binmoeller, 1995 [68] & 93 & 58 & $26 \%$ & $13 \%$ & $61 \%$ \\
\hline Rösch, 2002 [1] & 1018 & 58 & $24 \%$ & $16 \%$ & $60 \%$ \\
\hline Delhaye, 2004 [36] & 56 & 173 & $21 \%$ & $18 \%$ & $61 \%$ \\
\hline Tadenuma, 2005 [38] & 70 & 75 & $1 \%$ & $20 \%$ & $79 \%$ \\
\hline Inui, 2005 [45] & 555 & 44 & $4 \%$ & - & - \\
\hline Farnbacher, 2006 [37] & 98 & 46 & $23 \%$ & $18 \%$ & $59 \%$ \\
\hline
\end{tabular}

this RCT, endoscopic therapy was not optimal (extracorporeal shockwave lithotripsy [ESWL] and cumulative stenting were not used, endoscopic therapy was not repeated in the case of recurring symptoms). In the second RCT of endoscopic therapy vs. surgery [25, 26], the initial stenting period was relatively short as stents were removed when the stricture had disappeared on the pancreatogram, but resumed in the case of pain and stricture recurrence. This is in contrast to most other studies in which stenting is continued for 1 to 2 years. Moreover, this RCT included only patients with advanced chronic pancreatitis (most of them were opioid-dependent; $79 \%$ had strictures and stones). For these reasons, the results cannot be extrapolated to all patients with chronic pancreatitis.

Independent series from different parts of the world have reported the long-term outcome after endoscopic therapy in a total of 1890 patients with chronic pancreatitis; no pancreatic surgery was performed in $83 \%$ of them (Table 2 ). The reluctance of some gastroenterologists to consider surgery for the treatment of chronic pancreatitis (in particular as a first interventional procedure) may be explained by the relatively high morbidity and mortality associated with pancreatic surgery in the setting of chronic pancreatitis (18-53\% and 0-5\%, respectively, for resections [27], and 0-4\% mortality for MPD drainage [28]). In contrast, morbidity and mortality rates for endoscopic therapy for chronic pancreatitis are in the ranges $3-9 \%$ and $0-0.5 \%$, respectively (chronic pancreatitis is likely a protective factor against the most frequent complication of ERCP, i.e., pancreatitis) [1,29-31]. In painful chronic pancreatitis with mild changes at pancreatography according to the Cambridge classification [32], pancreatic sphincterotomy as a single therapeutic maneuver has been proposed but this has not been well studied. For example, mild chronic pancreatitis was recorded in 14/40 and 26/398 patients included in two series of endoscopic therapy for chronic pancreatitis but the outcome has not been reported for this particular subgroup of patients [30,33]. Therefore, our recommendation of endoscopic therapy as the first-line therapy for painful uncompli- cated chronic pancreatitis applies only to patients with moderate or marked changes of chronic pancreatitis at pancreatography according to the Cambridge classification.

Factors independently associated with long-term ( $\geq 2$ years) pain relief following endoscopic therapy of chronic pancreatitis include the location of obstructive calcifications in the head of the pancreas (most robust predictor of good outcome, identified in an RCT) [34], a short disease duration and a low frequency of pain attacks before endoscopic therapy, complete MPD stone clearance and absence of MPD stricture at initial endoscopic therapy, as well as discontinuation of alcohol and tobacco during follow-up [35-38]. Although MPD stones and strictures located in the tail of the pancreas are accessible to endoscopic therapy, this is more challenging compared with endoscopic therapy of similar lesions located in the head of the pancreas and clinical success is less certain. For that reason, when stones/dominant strictures are located in the pancreatic tail exclusively and are deemed responsible for pain, pancreatic tail resection is a possible firstintent option to be discussed with the patient and surgical team.

\section{Management of pancreatic stones}

\subsection{Definitions}

Different classifications of pancreatic stones have been proposed, based on radiopacity (radiolucent vs. radiopaque stones) or location (head, body, or tail; in the MPD, secondary ducts, or intraparenchymal) [39]. Successful stone fragmentation following ESWL has been defined as stones broken into fragments $\leq 2$ or $3 \mathrm{~mm}$ $[29,34,40]$, or by the demonstration of a decreased stone density at X-ray, an increased stone surface and an heterogeneity of the stone which may fill the MPD and adjacent side branches [41]. The Guideline group prefers the latter definition. 


\subsection{Methods and results}

\subsubsection{ESWL combined or not with ERCP}

Endoscopic attempts at MPD stone extraction without prior stone fragmentation are plagued with low success and relatively high morbidity rates; complications may be severe and may be observed even with pancreatic stones $<10 \mathrm{~mm}$ in diameter (Evidence level $2+$ ). ESWL consistently provides stone fragmentation in $90 \%$ of patients (Evidence level 1+); it facilitates endoscopic extraction of MPD stones (Evidence level 2+). Spontaneous elimination of stone fragments resulting from ESWL occurs in approximately $80 \%$ of patients. ESWL alone is more cost-effective than ESWL systematically combined with ERCP (Evidence level 1+).

For treating patients with uncomplicated painful chronic pancreatitis and radiopaque stones $\geq 5 \mathrm{~mm}$ obstructing the MPD, the ESGE recommends ESWL as a first step, immediately followed by endoscopic extraction of stone fragments. In centers with considerable experience with ESWL, ESWL alone should be preferred over ESWL systematically combined with ERCP (Recommendation grade B). Endoscopic attempts to extract radiopaque MPD stones without prior stone fragmentation should be considered only for stones $<5 \mathrm{~mm}$, preferably low in number, and located in the head or body of the pancreas. Intraductal lithotripsy should be attempted only after failure of ESWL (Recommendation grade $D$ ).

Nonsurgical clearance of stones obstructing the MPD can be achieved by ESWL alone, by ERCP alone (always including pancreatic sphincterotomy), or by a combination of these techniques. However, endoscopic attempts at MPD stone extraction using Dormia baskets without prior stone fragmentation have yielded unsatisfactory results: (i) a success rate of $9 \%$ was reported in a retrospective series of 125 patients [42]; (ii) in another retrospective multicenter series of 712 mechanical lithotripsies, the complication rate was three times higher for pancreatic compared with biliary stones [43].

ESWL is highly effective at fragmenting radiopaque pancreatic stones: in a systematic review of 11 series involving 1149 patients in total, the success of stone fragmentation by ESWL was $89 \%$ [44]. More recently, a large prospective single-center series achieved stone fragmentation in 935 (93\%) of 1006 patients [29]. Lower fragmentation rates have been reported, particularly in low case-volume centers; this may be due to technical factors and skill [45]. Performance of ESWL prior to endoscopic attempt at stone removal was independently associated with the success of MPD stone clearance in a retrospective study [35]. A meta-analysis of 17 studies (total of 491 patients) showed that ESWL is useful for clearing MPD stones and for decreasing pain [46].

In the majority of series, stones targeted by ESWL were mostly obstructive radiopaque MPD stones with a minimal diameter in the range of $2-5 \mathrm{~mm}[29,34,35,40,42,45,47,48]$. Factors significantly associated with the success of MPD stone clearance after ESWL included the presence of a single stone $[35,47]$, and confinement of calculi to the head of the pancreas [35]. These associations were found only in univariate analysis and in a minority of studies.

The use of ESWL alone for painful chronic pancreatitis was reported in two uncontrolled series and an RCT. The uncontrolled series included 350 patients followed up for 44 months; spontaneous MPD stone clearance was reported in $70-88 \%$ of patients and long-term pain relief in $78 \%$ of patients $[45,49]$. The RCT compared ESWL alone vs. ESWL followed by ERCP in 55 patients [34]. The only significant differences between groups were a longer hospital stay and a higher treatment cost in the ESWL plus ERCP group.
Morbidity related to ESWL alone or combined with ERCP was reviewed based on four large ( $>100$ patients) series: significant complications were reported in 104 of 1801 patients, including one death (morbidity and mortality rates, $5.8 \%$ and $0.05 \%$, respectively) $[29,38,41,45]$. Complications related to the treatment of chronic pancreatitis by ESWL alone were reported in three series that involved 165 patients; the morbidity rate was $6.0 \%[34,38,49]$. For both ESWL alone or ESWL plus ERCP, complications consisted of pancreatitis in the majority of cases.

Contraindications to ESWL include coagulation disorders, pregnancy, implanted cardiac pacemakers or defibrillators, and presence in the shockwave path of bone, calcified aneurysms, or lung tissue [50]. Of note, implanted cardiac pacemakers are not universally recognized as a contraindication to ESWL [51].

\subsubsection{Other methods}

Intraductal laser or electrohydraulic lithotripsy have provided discordant success rates for stone fragmentation (47-83\%) in small case series, after failure of ESWL to fragment stones [52, 53]. These techniques require nonstandard equipment and materials and are technically demanding; they are considered to be second-line interventions after failed ESWL.

Dissolution of pancreatic stones using various substances has been anecdotally reported $[54,55]$. The efficacy of such treatments has never been tested in comparative trials, and side effects may be significant. Therefore, stone dissolution therapy may have a role only in patients in whom all other, more conventional, methods have failed and who are not surgical candidates.

\section{Management of main pancreatic duct strictures $\nabla$}

\subsection{Definitions}

In chronic pancreatitis, MPD strictures may be single or multiple and classified as dominant or nondominant. Dominant MPD strictures are defined by the presence of at least one of the following characteristics: upstream MPD dilatation $\geq 6 \mathrm{~mm}$ in diameter, prevention of contrast medium outflow alongside a 6-Fr catheter inserted upstream from the stricture or abdominal pain during continuous infusion of a nasopancreatic catheter inserted upstream from the stricture with $1 \mathrm{~L}$ saline for $12-24 \mathrm{~h}$ [56]. Treatment of a dominant MPD stricture is defined as technically successful if at least one stent is inserted across the stricture (treatment by dilation alone has been abandoned). With regard to clinical success, many definitions have been used, ranging from doctor's opinion to validated pain scores. The ESGE recommends that future studies should use validated pain scores for both short-term and long-term evaluation of clinical success. For long-term evaluation, absence of pain (relapse) at 1 year post stent retrieval seems a reasonable and workable definition.

\subsection{Methods and results}

The reader is referred to a recent ESGE publication for an overview of the principles and technique of stricture treatment by continued dilation using temporary stent placement [57]. Points relevant to pancreatic stenting only are briefly discussed below:

- Pancreatic sphincterotomy (at the level of the major or minor papilla) has consistently been performed prior to MPD stenting in all large studies [37,58-65], in contrast to what has been reported for biliary stenting.

- Biliary sphincterotomy should be combined with pancreatic sphincterotomy only in selected cases according to an RCT, i.e. 
Table 3 Selected series of treatment with plastic stents for main pancreatic duct (MPD) strictures in chronic pancreatitis.

\begin{tabular}{|lllllll|}
\hline First author, year & $\mathbf{n}$ & Stent sizes, $\mathbf{F r}$ & $\begin{array}{l}\text { Follow-up, } \\
\text { months }\end{array}$ & Early pain relief, \% & $\begin{array}{l}\text { Sustained pain } \\
\text { relief, \% }\end{array}$ & $\begin{array}{l}\text { Patients undergoing } \\
\text { operation, } \%\end{array}$ \\
\hline Cremer, 1991 [58] & 75 & 10 & 37 & 94 & n.a. & 15 \\
\hline Ponchon, 1995 [59] & 23 & 10 & 14 & 74 & 52 & 15 \\
\hline Smits, 1995 [60] & 49 & 10 & 34 & 82 & 82 & 6 \\
\hline Binmoeller, 1995 [68] & 93 & $5-7-10$ & 58 & 74 & 65 & 26 \\
\hline Morgan, 2003 [69] & 25 & $5-7-8.5$ & n.a. & 65 & n.a. & n.a. \\
\hline Vitale, 2004 [61] & 89 & $5-7-10$ & 43 & 83 & 68 & 12 \\
\hline Eleftheriadis, 2005 [62] & 100 & $8.5-10$ & 69 & 70 & 62 & 4 \\
\hline Ishiara, 2006 [63] & 20 & 10 & 21 & 95 & 90 & n.a. \\
\hline Weber, 2007 [64] & 17 & $7-8.5-10-11.5$ & 24 & 89 & 83 & n.a. \\
\hline
\end{tabular}

n.a., not available.

in patients with cholangitis, jaundice (bilirubin $\geq 3 \mathrm{mg} / \mathrm{dL}$ ), a dilated CBD $(\geq 12 \mathrm{~mm})$ associated with elevated alkaline phosphatases (>2 upper limit of normal values), or in case of difficult access to the MPD [66].

- Stricture dilation is performed prior to stenting in most cases because chronic pancreatitis-related MPD strictures may be very tight and resilient. If bougies or balloons cannot pass the stricture, the Soehendra stent retriever may serve as a rescue option [67].

Pancreatic stenting is technically successful in $85-98 \%$ of attempted cases $[58-60,64]$; it is immediately followed by pain relief in $65-95 \%$ of patients [58-61,63-65,68]; during follow-up (14-58 months), pain relief has been reported in $32 \%-68 \%$ of patients $[25,37,59-61,63,64,68]$.

\subsubsection{Plastic stents}

Polyethylene 10-Fr pancreatic stents tailored to the shape of the MPD and length of the stricture are most commonly used. Occlusion of MPD stents usually occurs within 2-3 months (Evidence level 2-) while symptoms of chronic pancreatitis usually recur between 6 and 12 months (Evidence level $2+$ ). Thinner MPD stents $(\leq 8.5 \mathrm{Fr})$ are associated with more frequent hospitalizations for abdominal pain than 10-Fr stents. Placement of a single pancreatic plastic stent achieves MPD stricture resolution in nearly $60 \%$ of cases (Evidence level 2+) while simultaneous placement of multiple pancreatic stents was reported to be of additional benefit in a single study (Evidence level $2-$ ). Complications related to MPD stenting are usually mild and managed conservatively (Evidence level $2+$ ).

The ESGE recommends treating dominant MPD stricture by inserting a single 10-Fr plastic stent, with stent exchange planned within 1 year even in asymptomatic patients to prevent complications related to long-standing pancreatic stent occlusion (Recommendation grade C). Simultaneous placement of multiple, side-by-side, pancreatic stents could be applied more extensively, particularly in patients with MPD strictures persisting after 12 months of single plastic stenting. At this time point, the ESGE recommends that available options (e.g., endoscopic placement of multiple simultaneous MPD stents, surgery) be discussed by a multidisciplinary team (Recommendation grade $D)$.

- Table 3 summarizes selected studies of MPD stenting. Because MPD stenting for a short predefined (6-month) duration has been shown to be poorly effective [59], MPD stenting is performed for longer periods. Criteria used for terminating MPD stenting are as follows: (i) adequate pancreaticoduodenal outflow of contrast medium 1-2 minutes after ductal filling upstream from the stricture location, and (ii) easy passage of a 6-Fr catheter through the stricture location $[60,62,68]$. After prolonged MPD stenting, relapsing pain was observed in $36-48 \%$ of patients after "definitive" stent removal, re-stenting was indicated in $22-30 \%$ of patients, and $4-26 \%$ of patients had pancreatic surgery. A pancreas divisum anatomy might require longer/multiple stenting because it is associated with more frequent relapse of MPD stricture and of pain after stent removal compared with MPD stenting in patients with a fused pancreas [62].

Stent occlusion is the most frequent complication of MPD stenting; it is treated by stent exchange that may be performed either at regular intervals (e.g., 3 months) [61], or "on-demand," i.e., when symptoms develop $[62,68]$. The aim of an "on-demand" stent exchange schedule is to reduce the number of ERCP sessions; it is based on the fact that pain relapse most frequently occurs a long time after stent occlusion [69]. Drawbacks of the "ondemand" stent exchange schedule include rare occurrence of pancreatic abscesses and sepsis $[58,68]$, and failure to decrease the number of ERCP sessions (four to five in large studies) [62, 68].

Stents measuring 8.5 Fr or $10 \mathrm{Fr}$ in diameter are used in most studies. In a retrospective study of 163 patients, those who had received thin stents $(\leq 8.5 \mathrm{Fr}$ ) were 3.2 times more likely to be hospitalized for abdominal pain than those who had received 10 -Fr stents [70].

The role of multiple pancreatic stents was investigated in a single study that involved 19 patients [71]. The stricture was located in the head of the pancreas and it persisted after at least two placements of a single stent. A median of three simultaneous stents were inserted for a mean period of 7 months; persistent pain relief was noted in $84 \%$ of the patients after 38 months of followup.

The morbidity of pancreatic stenting is in the range of $6-39 \%$ $[37,58-62,64,65,68]$. It most frequently consists of mild pancreatitis; proximal or distal stent migration as well as pancreatic abscesses requiring surgery have rarely been reported.

\subsubsection{Self-expandable metallic stents (SEMSs)}

Patency of pancreatic SEMSs is short with regard to the life expectancy of patients with chronic pancreatitis (Evidence level 2-). Preliminary studies suggest that temporary placement of fully covered SEMS is safe and allows resolution of MPD strictures plus pain relief in a majority of patients but no follow-up longer than 1 year is available (Evidence level $2+$ ).

Uncovered SEMSs should not be inserted in MPD strictures (Recommendation grade D); temporary placement of fully covered SEMSs holds promise but it should be performed only in the setting of trials 
with approval of the institutional review board (Recommendation grade $\mathrm{C}$.

Historical series have shown that the patency duration of SEMSs left in place in the MPD was limited to approximately 1 year [72]. Therefore, SEMS insertion without scheduled removal is not performed anymore, as is the case for benign biliary strictures [19]. More recently, two centers have reported three prospective series that used temporary placement of fully covered SEMSs to treat chronic pancreatitis-related MPD strictures. Three different types of SEMS were inserted and left in place for 2-3 months in 51 patients [73-75]. Stent removal was successful in all of 46 attempted cases. No pain relapse was noted in 43 of 50 patients (86\%) during mean follow-up periods of 5 months following SEMS removal. Complications included SEMS migration in a single study ( $31 \%$ of 13 patients) and de novo focal MPD strictures (16\% of 32 patients) $[73,75]$.

\subsubsection{Endosonography-guided access and drainage (ESGAD) of the MPD}

Experience with ESGAD of the MPD is limited to a small number of reported cases with short follow-up. ESGAD was effective in obtaining MPD drainage and pain relief in selected patients with chronic pancreatitis, with morbidity usually being mild and no reported mortality (Evidence level 3). ESGAD of the MPD is indicated in carefully selected patients; patients considered for ESGAD should be referred to tertiary centers with appropriate equipment and expertise (Recommendation grade D).

Potential indications for ESGAD of the MPD include patients with a symptomatic MPD obstruction and failed conventional transpapillary MPD drainage. Briefly, the technique consists of puncturing the MPD through the gastric or duodenal wall, obtaining a pancreatogram and advancing a guide wire into the MPD to proceed with transpapillary (rendezvous technique) or transmural drainage [44].

Approximately 75 cases of ESGAD of the MPD have been reported [76-81]; follow-up for individual cases ranges from a few weeks up to 55 months (median, 1 year). Immediate pain relief after successful ESGAD of the MPD has been reported in a majority of patients with painful obstructive chronic pancreatitis (range, $50 \%$ $100 \%$ ). In the largest series to date $(n=36)$, complete or major pain relief was achieved in $69 \%$ of patients but the probability of remaining free of pain sharply dropped with time, to $20 \%$ after 450 days [79]. A malignant etiology for complete MPD obstruction should always be sought as 5 patients out of 36 in this series had a diagnosis of cancer within a year of the procedure [79].

The morbidity rate of ESGAD of the MPD varies between 0 and 44 $\%$; it mostly consists of relatively mild post-procedure pain, but severe pancreatitis, perforation, bleeding, and hematoma have been reported [76-81]. No procedure-related mortality has been reported. Migration and occlusion of stents frequently occur ( $20 \%$ to $55 \%$ of patients), necessitating endoscopic re-intervention. ESGAD is a technically challenging procedure [79].

\section{Endoscopic ultrasound-guided celiac plexus block $\nabla$}

EUS-guided celiac plexus block (CPB) provides temporary pain relief in approximately half of patients with chronic pancreatitis. EUS-guided CPB is superior to percutaneous CT-guided CPB in terms of pain control and of patient preference (Evidence level 1-).
The ESGE recommends considering CPB only as a second-line treatment for pain in chronic pancreatitis; EUS-guided CPB should be preferred over percutaneous CPB (Recommendation grade $C$ ).

During CPB, a mixture of corticoids with a local anesthetic is injected into celiac plexus nerves to disrupt the signaling of painful stimuli through pancreatic afferent nerves (celiac plexus neurolysis, it should be noted, uses alcohol and is reserved to patients with cancer-related pain) [82].

Meta-analyses have reported that EUS-guided CPB provides pain relief in $51 \%-59 \%$ of patients with painful chronic pancreatitis $[83,84]$; however, pain relief is transient [84]. For example, in a prospective series of 90 patients, the proportion of patients with pain relief decreased from $55 \%$ immediately after EUS-guided CPB to $10 \%$ at 24 weeks [85]. Because no RCT has included a sham group, a placebo effect cannot be excluded. A recent RCT has assessed the benefit of adding triamcinolone to bupivacaine for patients with painful chronic pancreatitis [86]; only $15 \%$ of the patients had a significant pain decrease at 1 month with addition of triamcinolone showing no difference.

In two RCTs, EUS was superior to CT guidance for CPB in terms of duration of pain relief and of patient preference $[87,88]$. Another theoretical advantage of the EUS-guided route is the absence of reported severe complications such as paraplegia and aortic pseudoaneurysms $[89,90]$. The most common complications of EUS-guided CPB include transient diarrhea, hypotension, and pain exacerbation, with an incidence of up to $33 \%$ [84].

\section{Pancreatic pseudocysts}

\subsection{Definitions}

Pancreatic pseudocysts (PPC) develop during the course of chronic pancreatitis in $20-40 \%$ of patients [91]. The Atlanta classification defines a PPC as a collection of pancreatic juice enclosed by a wall of fibrous granulation tissue, which arises as a consequence of acute pancreatitis, pancreatic trauma, or chronic pancreatitis [92]. It further distinguishes acute PPC (associated with acute pancreatitis more than 4 weeks previously) and chronic PPC (arising in patients with chronic pancreatitis and no antecedent acute pancreatitis). Endoscopic therapy of PPC consists of inserting a drain from the digestive lumen into the PPC, through the digestive wall ("transmural drainage"), through the papilla ("transpapillary drainage"), or a combination of these routes. Transpapillary PPC drainage is feasible only in the case of direct communication between the PPC and the MPD, which occurs in $40-66 \%$ of all PPCs [93-95]. Technical success is usually defined as the ability to insert at least one stent from the PPC to the digestive lumen [96,97], or resolution of the fluid collection but not necessarily of symptoms [98]. Short-term clinical success is usually defined as complete relief of the initial symptoms with a decrease in PPC diameter of at least $30-50 \%$ at 1 month [99].

\subsection{Indications for treatment}

Universally accepted indications for PPC treatment include the presence of symptoms (abdominal pain, gastric outlet obstruction, early satiety, weight loss, or jaundice) and infected or enlarging PPC. Compared with surgery, endoscopic drainage of uncomplicated PPC provides similar long-term results at a lower cost, with shorter hospital stay, and better quality of life during the first months following treatment. Procedure-related mortality is slightly lower with the endoscopic method (Evidence level 1+). 
The ESGE recommends endoscopic therapy as the first-line therapy for uncomplicated chronic PPCs for which treatment is indicated and that are within endoscopic reach (Recommendation grade A).

Besides the universally accepted indications for PPC treatment that are listed above [100], treatment for prophylaxis of potential PPC-related complications in asymptomatic patients has been advocated by some authors (although such complications occur in < $10 \%$ of patients during follow-up) [101,102]. Suggested indications for prophylactic treatment include compression of major vessels, intracystic hemorrhage, pancreaticopleural fistula, PPC > $5 \mathrm{~cm}$ without any regression after $>6$ weeks, cyst wall $>5 \mathrm{~mm}$, and PPC in the setting of chronic pancreatitis with advanced MPD changes or pancreaticolithiasis [103]. Treatment of asymptomatic PPC in chronic pancreatitis is supported by the low (0-9\%) rate of spontaneous PPC resolution in patients with established chronic pancreatitis in most series [104]. A single series reported a higher $(26 \%)$ resolution rate, which was observed after a long follow-up (median time to resolution, 29 weeks) [105].

In an RCT that compared endoscopic (EUS-guided) drainage vs. surgery for uncomplicated PPC, endoscopic drainage was significantly better than surgery in terms of cost, length of hospital stay, and quality of life up to 3 months post-procedure [106]. At a median follow-up of 18 months, clinical outcomes and quality of life were similar for both allocation groups. A large review of noncomparative historical series of endoscopic and surgical treatments that included 787 patients showed similar morbidity (13.3\% vs. $16.0 \%$, respectively) and long-term pseudocyst recurrence ( $10.7 \%$ vs. $9.8 \%$, respectively) but lower mortality with the endoscopic method ( $0.2 \%$ vs. $2.5 \%$, respectively) [107].

\subsection{Methods and results}

In the absence of luminal bulging, transmural drainage of PPC is feasible under EUS guidance only, with complication and success rates similar to those of conventional transmural drainage (Evidence level $1+$ ). Compared with transmural drainage, transpapillary drainage provides similar long-term success and is associated with fewer complications but it has been performed for relatively small collections only (generally $\leq 50 \mathrm{~mm}$ ). Compared with cystogastrostomy, cystoduodenostomy may provide better long-term success (Evidence level 2-). After transmural PPC drainage, early (2-month) stent removal is associated with a high likelihood of PPC recurrence (Evidence level 1-). Single transmural stents do not yield long-term success as frequently as multiple stents; straight transmural stents are associated with relatively frequent and severe complications (Evidence level 2-). Mortality associated with hemorrhage from pseudoaneurysms close to PPCs is high (Evidence level $1+$ ).

If transmural pseudocyst drainage is indicated in the absence of luminal bulging, it should be performed under EUS guidance (Recommendation grade A). For small collections communicating with the MPD in the head or body of the pancreas, the ESGE recommends attempting transpapillary drainage first. Cystoduodenostomy should be preferred over cystogastrostomy if both routes are deemed equally feasible. For transmural PPC drainage, the ESGE recommends inserting at least two double-pigtail plastic stents (Recommendation grade D); these should not be retrieved before cyst resolution as determined by cross-sectional imaging and not before at least 2 months of stenting (Recommendation grade B). In the case of portal hypertension, transmural drainage should be performed under EUS guidance. If arterial pseudoaneurysms are detected in the vicinity of the PPC, arterial embolization should be considered prior to PPC drainage (Recommendation grade $D$ ).
Transpapillary and transmural PPC drainages were compared in three nonrandomized studies that included 173 patients (chronic pancreatitis was diagnosed in $40-92 \%$ of them) $[95,98,108]$. Transpapillary drainage was used for smaller PPCs than transmural drainage. We calculated that transpapillary drainage was associated with lower morbidity (1/56 [1.8\%] vs. 18/117 [15.4\%] patients; $P=0.008)$ and similar long-term success (53/56 [94.6\%] vs. $105 / 117$ [89.7\%] patients; $P=0.391$ ) than transmural drainage.

For transmural PPC drainage, technical success was higher with EUS compared with conventional guidance in two RCTs $[97,109]$. All patients with failed conventional drainage had a successful EUS-guided drainage. Per-protocol analysis showed no difference between groups in terms of morbidity and clinical outcome. Failures of conventional drainage were related to the absence of intraluminal bulging, which is observed in approximately half of PPCs [95].

In a review of seven historical series that reported results separately for 121 patients treated by either cystoduodenostomy or cystogastrostomy, cystoduodenostomy more frequently yielded long-term success (59/71 [83.1\%] vs. 32/50 [64.0\%]; $P=0.019$ ), with identical morbidity (10\%) [110]. This could be related to a longer patency of cystoduodenal compared with cystogastric fistulas [110-112].

After transmural PPC drainage and PPC resolution, early stent removal was associated with more PPC recurrences compared with stent maintenance in an RCT of 28 patients ( 15 had chronic pancreatitis) [113]. In a retrospective study of 92 patients, PPC drainage with a single stent and a stenting duration $\leq 6$ weeks were independently associated with failure of endoscopic treatment (defined as severe procedure-related complication or need for another treatment modality) [96]. In this series, straight stents were used and they were associated with frequent bleeding (7\% of patients, with surgery required in two thirds of them) and stent migration. The authors advocated using double-pigtail stents.

Pseudoaneurysms may be detected in the setting of chronic pancreatitis, particularly where there is complication with a PPC [114]. In the largest review of hemorrhages associated with a PPC (126 episodes), overall mortality was 19\% [114]. Therefore, some authors recommend embolization of arterial pseudoaneurysms before attempting drainage of PPCs close to pseudoaneurysms [115]. Finally, extrahepatic portal hypertension develops during the course of chronic pancreatitis in $\geq 15 \%$ of patients [116]. Some authors recommend EUS-guided PPC drainage in cases of portal hypertension, to decrease the risk of bleeding [117]; this strategy has not been compared with conventional transmural drainage but it has been reported to be safe in a small series of patients [118].

\subsection{Particular case: complete MPD rupture}

PPC resolution in the case of a complete MPD rupture is achieved less frequently compared with clinical situations without complete MPD rupture; the risk of PPC relapse may also be higher. A stent bridging the MPD rupture (which may allow MPD healing) and a long stenting duration are associated with better long-term success (Evidence level 2-).

The ESGE recommends, besides transmural PPC drainage, attempting transpapillary bridging of MPD ruptures with a plastic stent. If the MPD rupture cannot be bridged, transmural stents should be left in place for as long as the disconnected pancreatic tail secretes pancreatic juice (typically, for years) (Recommendation grade D). 
In the case of complete MPD rupture without effective drainage, the disconnection of the pancreatic tail may lead to fluid accumulation. Initial PPC resolution after endoscopic treatment has been reported in $61 \%$ of 97 patients with a complete MPD rupture (with or without chronic pancreatitis) [119-122]. Bridging of complete MPD ruptures is possible in some cases [121,122]. A combination of transmural PPC drainage and a transpapillary stent bridging the MPD rupture may improve success [123]. In a retrospective study of 97 patients with partial or complete MPD rupture treated transpapillarily, factors associated with a successful outcome included a partial MPD rupture, a stent bridging the rupture and a long stenting duration [120]. In a series in which transmural stents were removed once PPC had resolved, half of the PPCs recurred [119]. In contrast, persisting long-term success was reported in 11 of 12 patients who had prolonged stenting [121].

\subsection{Complications}

Morbidity and mortality of endoscopic PPC drainage are approximately $13 \%$ and $0.3 \%$, respectively. Secondary PPC infection may complicate PPC drainage (Evidence level 1+); no data on the efficacy of antibiotic prophylaxis in this setting are available.

The ESGE recommends antibiotic prophylaxis for endoscopic PPC drainage (Recommendation grade $D$ ).

Figures stated above were reported in a recent review of 24 studies involving a total of 1126 patients with wide variations in morbidity between studies (3\%-34\%) [44, 103]. Major complications included hemorrhage, perforation, and infection; most of these were managed by nonoperative means, including local coagulation or arterial embolization for bleeding, repeat endoscopic drainage for secondary infection, and antibiotics for retroperitoneal perforation [99, 124,125]. Antibiotic administration immediately before transmural or transpapillary PPC drainage is recommended in recent guidelines based on expert opinion [126]. The decision about antibiotics continuation after the procedure should be guided by the adequacy of PPC drainage and the presence or absence of necrosis [100].

\section{Chronic pancreatitis-related biliary strictures}

\subsection{Definitions}

Biliary obstruction complicates the course of chronic pancreatitis in $3 \%-23 \%$ of patients [127]. Different cholangiographic types of chronic pancreatitis-related biliary strictures have been described, the type being suggestive of the etiology of biliary obstruction (fibrosis, compression by a pseudocyst or cancer) [128].

\subsection{Indications for treatment}

The ESGE recommends treating chronic pancreatitis-related biliary strictures in the case of symptoms, secondary biliary cirrhosis, biliary stones, progression of biliary stricture, or asymptomatic elevation of serum alkaline phosphatase ( $>2$ or 3 times the upper limit of normal values) and/or of serum bilirubin for longer than 1 month (Recommendation grade $A$ ).

The abovementioned indications are generally accepted [129].

\subsection{Methods and results}

Temporary placement of simultaneous multiple plastic stents is technically feasible in $>90 \%$ of patients with benign CBD strictures; it is the endoscopic technique that provides the highest long-term biliary patency rate in chronic pancreatitis-related biliary stric- tures (65\%); complete therapy requires approximately four ERCPS over a 12-month period. Possible stricture relapses after stenting are usually successfully re-treated by ERCP. Temporary placement of single plastic stents provides poorer patency rates; treatment with uncovered SEMSs is plagued with a high long-term morbidity; temporary placement of covered SEMSs is an investigational option (Evidence level $1+$ ). Some series of patients treated with plastic stents for CBD strictures related to alcoholic chronic pancreatitis have been reported to have a relatively high incidence of cholangitis, including fatal cases, due to poor patient compliance with scheduled stent exchanges. Comparative studies of surgical and endoscopic treatments in patients with benign biliary strictures related to a trauma have reported similar long-term results; no comparative data are available for chronic pancreatitis-related biliary strictures (Evidence level 2-).

The choice between endoscopic and surgical treatment should rely on local expertise, local or systemic patient co-morbidities (e.g., portal cavernoma, cirrhosis) and expected patient compliance with repeat endoscopic procedures (Recommendation grade D). If endoscopic therapy is elected, the ESGE recommends temporary (1-year) placement of multiple, side-by-side, plastic biliary stents (Recommendation grade A). Because of the risk of fatal septic complications, a recall system should be set up to care for patients who do not present for scheduled stent exchanges. In cases of relapsing stricture after stent removal at 1 year, the options available, including surgical biliary drainage, should be evaluated by a multidisciplinary team (Recommendation grade $D$ ).

A malignant etiology of the stricture should always be sought, at least by biliary brushing, as patients treated for supposedly benign chronic pancreatitis-related biliary stricture may have a final diagnosis of malignancy $[20,130]$. The principle of endoscopic treatment for biliary strictures consists of temporary stricture dilation using plastic stents (single or multiple side-by-side) or covered SEMSs. Definitive SEMS insertion has also been reported. In patients treated with plastic stents, various criteria have been used to decide on when to remove stents, including cholangiogram and a minimum stenting duration of 1 year [131]. Amongst benign biliary strictures, those related to chronic pancreatitis are the most difficult to treat by temporary biliary stenting: strictures less frequently resolve at the time of stent removal and they relapse more frequently during follow-up [130,132]. The presence of pancreatic calcifications has been associated with long-term failure of single plastic biliary stenting [133], but this factor may be less relevant if simultaneous multiple plastic stents are used [134].

Short-term (1-month) results for biliary stenting are similar for plastic stents and SEMSs in all respects, including success rates and complication rates (approximately $5 \%$ ). For the selection of particular models of stents, the reader is referred to other recent ESGE Guidelines [19,57].

Long-term results of temporary biliary stenting for chronic pancreatitis-related biliary strictures are summarized in $\bullet$ Table 4. Successful treatment was reported in $31 \%$ of 350 patients with single plastic stents and $62 \%$ of 50 patients with simultaneous multiple plastic stents. A single nonrandomized series has compared long-term results after temporary treatment with single vs. multiple simultaneous plastic stents; it showed overall clinical success in $24 \%$ vs. $92 \%$ patients, respectively ( $\mathrm{P}<0.01$ ), after similar follow-up durations [134].

In series that used simultaneous multiple plastic stents, stent exchanges were scheduled at 3-month intervals and the mean observed stenting duration was 12-21 months (mean number of 
Table 4 Selected series of temporary stenting for common bile duct (CBD) strictures in chronic pancreatitis.

\begin{tabular}{|c|c|c|c|c|c|c|}
\hline First author, year & n & $\begin{array}{l}\text { Long-term } \\
\text { success, \% }\end{array}$ & $\begin{array}{l}\text { Stenting duration, } \\
\text { months }\end{array}$ & $\begin{array}{l}\text { Stent dysfunction } \\
\text { of any cause per } \\
\text { patient, \% }\end{array}$ & $\begin{array}{l}\text { Follow-up post } \\
\text { stent removal, } \\
\text { months }\end{array}$ & $\begin{array}{l}\text { Patients who } \\
\text { underwent surgi- } \\
\text { cal drainage, \% }\end{array}$ \\
\hline \multicolumn{7}{|l|}{ Single plastic stent } \\
\hline Deviere, 1990 [155] & 25 & 12 & n.a. & 72 & 14 & 24 \\
\hline Barthet, 1994 [156] & 19 & 10 & 10 & NA & 18 & 21 \\
\hline Smits, 1996 [157] & 58 & 28 & 10 & 64 & 49 & 28 \\
\hline Vitale, 2000 [158] & 25 & $80^{1}$ & 13 & 20 & 32 & 8 \\
\hline Farnbacher, 2000 [159] & 31 & 32 & 10 & 52 & 28 & 6 \\
\hline Eickoff, 2001 [160] & 39 & 31 & 9 & 43 & 58 & 28 \\
\hline Kahl, 2003 [133] & 61 & 26 & 12 & 34 & 40 & 49 \\
\hline Catalano, 2004 [134] & 34 & 24 & 21 & 41 & 50 & 41 \\
\hline Cahen, 2005 [161] & 58 & 38 & 9 & 48 & 45 & 28 \\
\hline \multicolumn{7}{|l|}{ Multiple plastic stents } \\
\hline Draganov, 2002 [136] & 9 & 44 & 14 & n.a. & 48 & n.a. \\
\hline Pozsar, 2004 [135] & 29 & 60 & 21 & n.a. ${ }^{2}$ & 12 & 13 \\
\hline Catalano, 2004 [134] & 12 & 92 & 14 & 8 & 47 & 8 \\
\hline \multicolumn{7}{|l|}{ Covered SEMS } \\
\hline Cahen, $2008^{3}$ [140] & 6 & 50 & 5 & 33 & 28 & 17 \\
\hline Behm, $2009^{4}[144]$ & 20 & 80 & 5 & 5 & 22 & 0 \\
\hline Mahajan, $2009^{5}$ [132] & 19 & n.a. & 3 & 11 & 4 & n.a. \\
\hline
\end{tabular}

SEMS, self-expandable metal stent; n.a., not available

${ }^{1}$ The unusually high success rate reported by Vitale et al. was related, according to the authors, to a low prevalence of calcifying chronic pancreatitis in their series ( $23 \%$ vs. $60-70 \%$ in other series)

220 episodes of cholangitis were reported.

${ }^{3}$ Fully covered Hanaro stent (Hanaro, M.I.Tech Co., Ltd., Seoul, South Korea).

4 Partially covered Wallstent (Boston Scientific, Natick, Massachusetts, USA).

${ }^{5}$ Fully covered Viabil stent (Conmed, Utica, New York, USA).

ERCPs, 4.0-4.7) [134-136]. According to a recent retrospective study, the interval between stent exchanges could be extended [137]. However, in patients with alcoholic chronic pancreatitis, compliance with stent exchange may be problematic: in a retrospective series of 14 patients, only two (14.3\%) patients presented for elective stent exchanges although written instructions were given to the patients and primary care physicians for doing so [138]. Another retrospective series reported an observed mean interval between stent exchanges of 6.4 months although these were scheduled at 3-month intervals; there were at least 20 episodes of cholangitis in a total of 29 patients, of which two were fatal [135]. Of note, in the latter series, stents were exchanged at ERCP only if they were clogged. Protocols aiming at lowering stenting duration and/or the number of ERCPs are being explored:

- In patients with biliary strictures complicating orthotopic liver transplantation, plastic stents were exchanged with a higher number of stents every 2 weeks until complete waist disappearance at the level of the anastomosis, and were then left in place for 3 months [139].

- In patients with chronic pancreatitis, temporary treatment with partially or fully covered SEMSs has been reported in small series of patients using different SEMS models and with different results. Limitations include failure to remove stents and short follow-up after covered SEMS removal in currently available studies [140].

- Definitive insertion of uncovered or partially covered SEMS has been abandoned because of disappointing long-term results in benign biliary strictures [141-143].

No comparison of various stenting durations has been reported in the literature (scheduled stenting duration with multiple plastic stents and covered SEMSs has generally been for 1 year and for 3-6 months, respectively) [132,134-136,140,144]. Stent dys- function has been reported in $8-69 \%$ and $5-33 \%$ of patients treated with temporary insertion of multiple plastic stents and of covered SEMSs, respectively [132,134-136,140,144]. The costs of these two methods have not been compared.

No study has compared endoscopic biliary stenting vs. surgical biliodigestive anastomosis for chronic pancreatitis-related biliary stricture. Two nonrandomized studies have compared endoscopy vs. surgery for the treatment of benign biliary strictures related to trauma (cholecystectomy in most cases). One of these studies reported similar morbidity (35\% vs. 26\%) and absence of stricture relapse (17\% in both groups) during follow-up in 101 patients [145]. The other study found that endoscopic treatment was associated with a higher morbidity rate ( $45 \%$ vs. $9 \%$; $P=0.01$ ), shorter total hospital stay ( 6 vs. 11 days; $P=0.001$ ), and similar success at $\geq 5$ years ( $80 \%$ vs. $77 \%$ ) in 42 patients [146].

\section{Treatment of chronic pancreatitis in children}

The main indication for endoscopic therapy of chronic pancreatitis in children is pain. (Evidence level $2+$ ). After endoscopic therapy for chronic pancreatitis the majority of children have lesser symptoms and less hospital admission during long-term follow-up. The main complication of endoscopic therapy for chronic pancreatitis in children is acute pancreatitis, which is usually mild or moderate. (Evidence level $2-$ ).

The ESGE recommends endoscopic therapy as a first-line therapy for chronic pancreatitis in children starting at 8 years in the same conditions as in adults (Recommendation grade C).

A recent, retrospective, large Danish study of chronic pancreatitis in young adults $(<30$ years old) showed that the standardized prevalence ratio of chronic pancreatitis increased between 1980 - 1984 and 2000-2004 [147]. The most frequent etiologies 
are idiopathic and genetic; a retrospective case series from Germany found genetic mutations in $30 \%$ of 146 patients with chronic pancreatitis younger than 18 years [148]. The disease usually presents as episodes of moderate abdominal pain [149]; a retrospective study showed that, compared with adults, pediatric patients had less severe chronic pancreatitis stages, and a lower prevalence of pseudocysts, of calcifications, and of chronic pancreatitis-related CBD biliary strictures [150].

Three retrospective case series evaluated endoscopic therapy for pain in children with chronic pancreatitis [151-153]. In two studies $[151,153]$, the majority of patients had a subjective improvement of their disease and a decrease in hospital admissions following endoscopic therapy. In the third study, recurrence of a flare of chronic pancreatitis was more frequent after endoscopic as compared with surgical treatment ( $75 \%$ of 12 patients vs. $39 \%$ of 25 patients, respectively). Regarding treatment-related complications, mild and moderate acute pancreatitis was encountered in $17 \%$ and $6 \%$ of cases, respectively $[151,153]$.

\section{Use of the Guideline}

The disclaimer regarding ESGE guidelines applies to this Guideline [154].

Competing interests: Guido Costamagna, Nageshwar Reddy, Jacques Devière, and Marco Bruno have received research support from Cook Endoscopy Inc., Limerick, Ireland, and from Boston Scientific, Natick, Massachusetts, USA. Nageshwar Reddy also received research support from TaeWoong Medical, Korea. Marco Bruno also received research support from MiTech, Seoul, South Korea.

\section{Institutions}

${ }^{1}$ Service of Gastroenterology and Hepatology, Geneva University Hospitals, Geneva, Switzerland

2 Department of Gastroenterology and Hepato-Pancreatology, Erasme University Hospital, Brussels, Belgium

${ }^{3}$ Digestive Endoscopy Unit, Catholic University, Rome, Italy

${ }^{4}$ Department of Gastroenterology and Hepatology, University Hospital

of Santiago de Compostela, Santiago de Compostela, Spain

${ }^{5}$ Department of Gastroenterology and Hepatology, Erasmus Medical Center, Rotterdam, The Netherlands

${ }^{6}$ Fribourg, Switzerland

${ }^{7}$ Department of Gastroenterology, Centre Hospitalier de l'Université de

Montréal, Montréal, Québec, Canada

${ }^{8}$ Department of Gastroenterology, Asian Institute of Gastroenterology, Hyderabad, India

${ }^{9}$ Department of Gastroenterology and Hepatology, Academic Medical Center, Amsterdam, The Netherlands

${ }^{10}$ Hôpital Edouard Herriot, Department of Digestive Diseases, Lyon, France

\section{References}

1 Rösch T, Daniel S, Scholz M et al. Endoscopic treatment of chronic pancreatitis: a multicenter study of 1000 patients with long-term followup. Endoscopy 2002; 34: 765-771

2 Boustière C, Veitch A, Vanbiervliet $G$ et al. Endoscopy and antiplatelet agents. European Society of Gastrointestinal Endoscopy (ESGE) Guideline. Endoscopy 2011; 43: 445-461

3 Sica GT, Braver J, Cooney MJ et al. Comparison of endoscopic retrograde cholangiopancreatography with MR cholangiopancreatography in patients with pancreatitis. Radiology 1999; 210: 605-610

4 Hintze RE, Adler A, Veltzke W et al. Clinical significance of magnetic resonance cholangiopancreatography (MRCP) compared to endoscopic retrograde cholangiopancreatography (ERCP). Endoscopy 1997; 29: $182-187$

5 Schlaudraff E, Wagner H-J, Klose KJ et al. Prospective evaluation of the diagnostic accuracy of secretin-enhanced magnetic resonance cholan- giopancreaticography in suspected chronic pancreatitis. Magn Reson Imaging 2008; 26: 1367-1373

6 Morgan DE, Baron TH, Smith JK et al. Pancreatic fluid collections prior to intervention: evaluation with MR imaging compared with CT and US. Radiology 1997; 203: $773-778$

7 Hart AR, Kennedy H, Harvey I. Pancreatic cancer: a review of the evidence on causation. Clin Gastroenterol Hepatol 2008; 6: 275-282

8 Varadarajulu S, Tamhane A, Eloubeidi MA. Yield of EUS-guided FNA of pancreatic masses in the presence or the absence of chronic pancreatitis. Gastrointest Endosc 2005; 62: 728 - 736 ; quiz 751, 753

9 Arvanitakis M, Van Laethem J-L, Parma J et al. Predictive factors for pancreatic cancer in patients with chronic pancreatitis in association with K-ras gene mutation. Endoscopy 2004; 36: 535 - 542

10 Bipat S, Phoa SSKS, van Delden OM et al. Ultrasonography, computed tomography and magnetic resonance imaging for diagnosis and determining resectability of pancreatic adenocarcinoma: a meta-analysis. J Comput Assist Tomogr 2005; 29: 438-445

11 Balthazar EJ. Pancreatitis associated with pancreatic carcinoma. Preoperative diagnosis: role of $\mathrm{CT}$ imaging in detection and evaluation. Pancreatology 2005; 5: 330-344

12 Yamada Y, Mori H, Matsumoto $S$ et al. Pancreatic adenocarcinoma versus chronic pancreatitis: differentiation with triple-phase helical CT. Abdom Imaging 2010; 35: 163-171

13 Gerstenmaier JF, Malone DE. Mass lesions in chronic pancreatitis: benign or malignant? An "evidence-based practice" approach. Abdom Imaging 2011; 36: 569-577

14 Ardengh JC, Lopes CV, Campos AD et al. Endoscopic ultrasound and fine needle aspiration in chronic pancreatitis: differential diagnosis between pseudotumoral masses and pancreatic cancer. JOP 2007; 8 : $413-421$

15 Kaufman AR, Sivak MV. Endoscopic ultrasonography in the differential diagnosis of pancreatic disease. Gastrointest Endosc 1989; 35: $214-$ 219

16 Fritscher-Ravens A, Brand L, Knöfel WT et al. Comparison of endoscopic ultrasound-guided fine needle aspiration for focal pancreatic lesions in patients with normal parenchyma and chronic pancreatitis. Am J Gastroenterol 2002; 97: 2768-2775

17 Krishna NB, Mehra M, Reddy AV et al. EUS/EUS-FNA for suspected pancreatic cancer: influence of chronic pancreatitis and clinical presentation with or without obstructive jaundice on performance characteristics. Gastrointest Endosc 2009; 70: 70 - 79

18 Dumonceau J-M, Polkowski M, Larghi A et al. Indications, results, and clinical impact of endoscopic ultrasound (EUS)-guided sampling in gastroenterology: European Society of Gastrointestinal Endoscopy (ESGE) Clinical Guideline. Endoscopy 2011; 43: 897-912

19 Dumonceau JM, Tringali A, Blero D et al. Biliary stenting: indications, choice of stents and results. ESGE Clinical Guideline. Endoscopy 2012; 44: $277-298$

20 Dumonceau J-M, Macias GomezC, Casco C et al. Grasp or brush for biliary sampling at endoscopic retrograde cholangiography? A blinded randomized controlled trial Am J Gastroenterol 2008; 103: 333-340

21 Shimosegawa T, Chari ST, Frulloni L et al. International consensus diagnostic criteria for autoimmune pancreatitis: guidelines of the International Association of Pancreatology. Pancreas 2011; 40: 352 - 358

22 Tanaka M, Chari S, Adsay V et al. International consensus guidelines for management of intraductal papillary mucinous neoplasms and mucinous cystic neoplasms of the pancreas. Pancreatology 2006; 6: 17-32

23 Talamini G, Zamboni G, Salvia $R$ et al. Intraductal papillary mucinous neoplasms and chronic pancreatitis. Pancreatology 2006; 6: 626-634

24 Díte $P$, Ruzicka $M$, Zboril $V$ et al. A prospective, randomized trial comparing endoscopic and surgical therapy for chronic pancreatitis. Endoscopy 2003; 35: 553-558

25 Cahen DL, Gouma DJ, Nio Y et al. Endoscopic versus surgical drainage of the pancreatic duct in chronic pancreatitis. N Engl J Med 2007; 356: 676-684

26 Cahen DL, Gouma DJ, Laramée P et al. Long-term outcomes of endoscopic vs surgical drainage of the pancreatic duct in patients with chronic pancreatitis. Gastroenterology 2011; 141: 1690-1695

27 Diener MK, Rahbari NN, Fischer L et al. Duodenum-preserving pancreatic head resection versus pancreatoduodenectomy for surgical treatment of chronic pancreatitis: a systematic review and meta-analysis. Ann Surg 2008; 247: 950-961

28 Isaji S. Has the Partington procedure for chronic pancreatitis become a thing of the past? A review of the evidence J Hepatobiliary Pancreat Sci 2010; 17: $763-769$ 
29 Tandan M, Reddy DN, Santosh D et al. Extracorporeal shock wave lithotripsy and endotherapy for pancreatic calculi - a large single center experience. Indian J Gastroenterol 2010; 29: 143-148

30 Hookey LC, RioTinto R, Delhaye M et al. Risk factors for pancreatitis after pancreatic sphincterotomy: a review of 572 cases. Endoscopy 2006; 38: $670-676$

31 Dumonceau J-M, Andriulli A, Deviere J et al. European Society of Gastrointestinal Endoscopy (ESGE) Guideline: prophylaxis of post-ERCP pancreatitis. Endoscopy 2010; 42: $503-515$

32 Sarner M, Cotton PB. Classification of pancreatitis. Gut 1984; 25: 756 759

33 Okolo PI, Pasricha PJ, Kalloo AN. What are the long-term results of endoscopic pancreatic sphincterotomy? Gastrointest Endosc 2000; 52: $15-19$

34 Dumonceau J-M, Costamagna G, Tringali A et al. Treatment for painful calcified chronic pancreatitis: extracorporeal shock wave lithotripsy versus endoscopic treatment: a randomised controlled trial. Gut 2007; 56: $545-552$

35 Dumonceau JM, Devière J, Le Moine $O$ et al. Endoscopic pancreatic drainage in chronic pancreatitis associated with ductal stones: longterm results. Gastrointest Endosc 1996; 43: 547 - 555

36 Delhaye $M$, Arvanitakis $M$, Verset $G$ et al. Long-term clinical outcome after endoscopic pancreatic ductal drainage for patients with painful chronic pancreatitis. Clin Gastroenterol Hepatol 2004; 2: 1096-1106

37 Farnbacher MJ, Mühldorfer S, Wehler M et al. Interventional endoscopic therapy in chronic pancreatitis including temporary stenting: a definitive treatment? Scand J Gastroenterol 2006; 41: 111 -117

38 Tadenuma H, Ishihara T, Yamaguchi $T$ et al. Long-term results of extracorporeal shockwave lithotripsy and endoscopic therapy for pancreatic stones. Clin Gastroenterol Hepatol 2005; 3: 1128-1135

39 Mariani A, Bernard JP, Provansal-Cheylan $M$ et al. Differences of pancreatic stone morphology and content in patients with pancreatic lithiasis. Dig Dis Sci 1991; 36: 1509-1516

40 Brand B, Kahl M, Sidhu $S$ et al. Prospective evaluation of morphology, function, and quality of life after extracorporeal shockwave lithotripsy and endoscopic treatment of chronic calcific pancreatitis. Am J Gastroenterol 2000; 95: $3428-3438$

41 Delhaye $M$, Vandermeeren A, Baize $M$ et al. Extracorporeal shock-wave lithotripsy of pancreatic calculi. Gastroenterology 1992; 102: 610620

42 Farnbacher MJ, Schoen C, Rabenstein $T$ et al. Pancreatic duct stones in chronic pancreatitis: criteria for treatment intensity and success. Gastrointest Endosc 2002; 56: 501 - 506

43 Thomas M, Howell DA, Carr-Locke D et al. Mechanical lithotripsy of pancreatic and biliary stones: complications and available treatment options collected from expert centers. Am J Gastroenterol 2007; 102: $1896-1902$

44 Nguyen-Tang T, Dumonceau J-M. Endoscopic treatment in chronic pancreatitis, timing, duration and type of intervention. Best Pract Res Clin Gastroenterol 2010; 24: 281 - 298

45 Inui K, Tazuma S, Yamaguchi T et al. Treatment of pancreatic stones with extracorporeal shock wave lithotripsy: results of a multicenter survey. Pancreas 2005; 30: 26 - 30

46 Guda NM, Partington S, Freeman ML. Extracorporeal shock wave lithotripsy in the management of chronic calcific pancreatitis: a meta-analysis. JOP 2005; 6: 6-12

47 Adamek HE, Jakobs R, Buttmann A et al. Long term follow up of patients with chronic pancreatitis and pancreatic stones treated with extracorporeal shock wave lithotripsy. Gut 1999; 45: 402-405

48 Kozarek RA, Brandabur JJ, Ball TJ et al. Clinical outcomes in patients who undergo extracorporeal shock wave lithotripsy for chronic calcific pancreatitis. Gastrointestinal Endoscopy 2002; 56: 496- 500

49 Ohara H, Hoshino M, Hayakawa $T$ et al. Single application extracorporeal shock wave lithotripsy is the first choice for patients with pancreatic duct stones. Am J Gastroenterol 1996; 91: 1388-1394

50 Delhaye $M$. Extracorporeal shock wave lithotripsy for pancreatic stones. UpToDate 2011: 1 - 9 Available at: http://wwwuptodatecom/ contents/extracorporeal-shock-wave-lithotripsy-for-pancreaticstones? source=search_result\&selectedTitle=1\%7E150 Accessed: Apr 302011

51 Platonov MA, Gillis AM, Kavanagh KM. Pacemakers, implantable cardioverter/defibrillators, and extracorporeal shockwave lithotripsy: evidence-based guidelines for the modern era. J Endourol 2008; 22 : $243-247$
52 Hirai T, Goto H, Hirooka Yet al. Pilot study of pancreatoscopic lithotripsy using a 5-fr instrument: selected patients may benefit. Endoscopy 2004; 36: $212-216$

53 Howell DA, Dy RM, Hanson BL et al. Endoscopic treatment of pancreatic duct stones using a 10F pancreatoscope and electrohydraulic lithotripsy. Gastrointest Endosc 1999; 50: 829-833

54 Noda A, Shibata T, Hamano H et al. Trimethadione (troxidone) dissolves pancreatic stones. Lancet 1984; 2: $351-353$

55 Sarles H, Verine H, Lohse J et al. [Dissolution of pancreatic calculi during prolonged oral administration of citrate]. Nouv Presse Med 1979; 8: $1767-1768$

56 Delhaye M, Matos C, Devière J. Endoscopic management of chronic pancreatitis. Gastrointest Endosc Clin N Am 2003; 13: 717-742

57 Dumonceau JM, Heresbach D, Deviere J et al. Biliary stents: models and methods for endoscopic stenting European Society of Gastrointestinal Endoscopy (ESGE) Technology Review. Endoscopy 2011; 43: 617-626

58 Cremer $M$, Devière J, Delhaye $M$ et al. Stenting in severe chronic pancreatitis: results of medium-term follow-up in seventy-six patients. Endoscopy 1991; 23: $171-176$

59 Ponchon T, Bory RM, Hedelius F et al. Endoscopic stenting for pain relief in chronic pancreatitis: results of a standardized protocol. Gastrointest Endosc 1995; 42: $452-456$

60 Smits ME, Badiga SM, Rauws EA et al. Long-term results of pancreatic stents in chronic pancreatitis. Gastrointest Endosc 1995; 42: 461 - 467

61 Vitale GC, Cothron K, Vitale EA et al. Role of pancreatic duct stenting in the treatment of chronic pancreatitis. Surg Endosc 2004; 18: 1431 1434

62 Eleftherladis N, Dinu F, Delhaye M et al. Long-term outcome after pancreatic stenting in severe chronic pancreatitis. Endoscopy 2005; 37 : $223-230$

63 Ishihara T, Yamaguchi T, Seza K et al. Efficacy of s-type stents for the treatment of the main pancreatic duct stricture in patients with chronic pancreatitis. Scand J Gastroenterol 2006; 41: 744-750

64 Weber A, Schneider J, Neu B et al. Endoscopic stent therapy for patients with chronic pancreatitis: results from a prospective follow-up study. Pancreas 2007; 34: 287 - 294

65 Boursier J, Quentin V, Le Tallec V et al. Endoscopic treatment of painful chronic pancreatitis: Evaluation of a new flexible multiperforated plastic stent. Gastroenterol Clin Biol 2008; 32: 801 - 805

66 Kim MH, Myung SJ, Kim YS et al. Routine biliary sphincterotomy may not be indispensable for endoscopic pancreatic sphincterotomy. Endoscopy 1998; 30: $697-701$

67 Ziebert JJ, DiSario JA. Dilation of refractory pancreatic duct strictures: the turn of the screw. Gastrointest Endosc 1999; 49: 632-635

68 Binmoeller KF, Jue P, Seifert $H$ et al. Endoscopic pancreatic stent drainage in chronic pancreatitis and a dominant stricture: long-term results. Endoscopy 1995; 27: $638-644$

69 Morgan DE, Smith JK, Hawkins K et al. Endoscopic stent therapy in advanced chronic pancreatitis: relationships between ductal changes, clinical response, and stent patency. Am J Gastroenterol 2003; 98: $821-826$

70 Sauer BG, Gurka MJ, Ellen K et al. Effect of pancreatic duct stent diameter on hospitalization in chronic pancreatitis: does size matter? Pancreas 2009; 38: $728-731$

71 Costamagna $G$, Bulajic $M$, Tringali A et al. Multiple stenting of refractory pancreatic duct strictures in severe chronic pancreatitis: long-term results. Endoscopy 2006; 38: 254-259

72 Eisendrath P, Devière J. Expandable metal stents for benign pancreatic duct obstruction. Gastrointest Endosc Clin N Am 1999; 9: 547-554

73 Park DH, Kim M-H, Moon S-H et al. Feasibility and safety of placement of a newly designed, fully covered self-expandable metal stent for refractory benign pancreatic ductal strictures: a pilot study (with video). Gastrointest Endosc 2008; 68: $1182-1189$

74 Sauer B, Talreja J, Ellen K et al. Temporary placement of a fully covered self-expandable metal stent in the pancreatic duct for management of symptomatic refractory chronic pancreatitis: preliminary data (with videos). Gastrointest Endosc 2008; 68: 1173 - 1178

75 Moon S-H, Kim M-H, Park DH et al. Modified fully covered self-expandable metal stents with antimigration features for benign pancreaticduct strictures in advanced chronic pancreatitis, with a focus on the safety profile and reducing migration. Gastrointest Endosc 2010; 72: $86-91$

76 François E, Kahaleh M, Giovannini $M$ et al. EUS-guided pancreaticogastrostomy. Gastrointest Endosc 2002; 56: 128-133 
77 Mallery S, Matlock J, Freeman ML. EUS-guided rendezvous drainage of obstructed biliary and pancreatic ducts: Report of 6 cases. Gastrointest Endosc 2004; 59: $100-107$

78 Will U, Fueldner F, Thieme A-K et al. Transgastric pancreatography and EUS-guided drainage of the pancreatic duct. J Hepatobiliary Pancreat Surg 2007; 14: 377-382

79 Tessier G, Bories E, Arvanitakis $M$ et al. EUS-guided pancreatogastrostomy and pancreatobulbostomy for the treatment of pain in patients with pancreatic ductal dilatation inaccessible for transpapillary endoscopic therapy. Gastrointest Endosc 2007; 65: 233-241

80 Kahaleh M, Hernandez AJ, Tokar J et al. EUS-guided pancreaticogastrostomy: analysis of its efficacy to drain inaccessible pancreatic ducts. Gastrointest Endosc 2007; 65: 224-230

81 Brauer BC, Chen YK, Fukami N et al. Single-operator EUS-guided cholangiopancreatography for difficult pancreaticobiliary access (with video). Gastrointest Endosc 2009; 70: 471 - 479

82 Pateman J, Williams MP, Filshie J. Retroperitoneal fibrosis after multiple coeliac plexus blocks. Anaesthesia 1990; 45: 309-310

83 Puli SR, Reddy JBK, Bechtold ML et al. EUS-guided celiac plexus neurolysis for pain due to chronic pancreatitis or pancreatic cancer pain: a meta-analysis and systematic review Dig Dis Sci 2009; 54: 2330 - 2337

84 Kaufman M, Singh G, Das $S$ et al. Efficacy of endoscopic ultrasoundguided celiac plexus block and celiac plexus neurolysis for managing abdominal pain associated with chronic pancreatitis and pancreatic cancer. J Clin Gastroenterol 2010; 44: 127-134

85 Gress F, Schmitt C, Sherman S et al. Endoscopic ultrasound-guided celiac plexus block for managing abdominal pain associated with chronic pancreatitis: a prospective single center experience. Am J Gastroenterol 2001; 96: 409-416

86 Stevens T, Costanzo A, Lopez $R$ et al. Adding triamcinolone to endoscopic ultrasound-guided celiac plexus blockade does not reduce pain in patients with chronic pancreatitis. Clin Gastroenterol Hepatol 2012; 10: $186-191$ e181

87 Gress F, Schmitt C, Sherman S et al. A prospective randomized comparison of endoscopic ultrasound- and computed tomography-guided celiac plexus block for managing chronic pancreatitis pain. Am J Gastroenterol 1999; 94: 900-905

88 Santosh D, Lakhtakia S, Gupta R et al. Clinical trial: a randomized trial comparing fluoroscopy guided percutaneous technique vs. endoscopic ultrasound guided technique of coeliac plexus block for treatment of pain in chronic pancreatitis. Aliment Pharmacol Ther 2009; 29: 979 984

89 Sett SS, Taylor DC. Aortic pseudoaneurysm secondary to celiac plexus block. Ann Vasc Surg 1991; 5: 88-91

90 Davies $D D$. Incidence of major complications of neurolytic coeliac plexus block. J R Soc Med 1993; 86: 264-266

91 Andrén-Sandberg A, Dervenis C. Pancreatic pseudocysts in the 21st century. Part I: classification, pathophysiology, anatomic considerations and treatment. JOP 2004; 5: 8-24

92 Bradley EL. A clinically based classification system for acute pancreatitis. Summary of the International Symposium on Acute Pancreatitis, Atlanta, Ga, September 11 through 13, 1992. Arch Surg 1993; 128: $586-590$

93 Barkin JS, Hyder SA. Changing concepts in the management of pancreatic pseudocysts. Gastrointest Endosc 1989; 35: 62 - 64

94 Baron TH, Harewood GC, Morgan DE et al. Outcome differences after endoscopic drainage of pancreatic necrosis, acute pancreatic pseudocysts, and chronic pancreatic pseudocysts. Gastrointest Endosc 2002; 56: $7-17$

95 Barthet M, Lamblin G, Gasmi M et al. Clinical usefulness of a treatment algorithm for pancreatic pseudocysts. Gastrointest Endosc 2008; 67: $245-252$

96 Cahen D, Rauws E, Fockens $P$ et al. Endoscopic drainage of pancreatic pseudocysts: long-term outcome and procedural factors associated with safe and successful treatment. Endoscopy 2005; 37: 977-983

97 Park DH, Lee SS, Moon S-H et al. Endoscopic ultrasound-guided versus conventional transmural drainage for pancreatic pseudocysts: a prospective randomized trial. Endoscopy 2009; 41: 842 - 848

98 Hookey LC, Debroux S, Delhaye $M$ et al. Endoscopic drainage of pancreatic-fluid collections in 116 patients: a comparison of etiologies, drainage techniques, and outcomes. Gastrointest Endosc 2006; 63: 635643

99 Kahaleh M, Shami VM, Conaway MR et al. Endoscopic ultrasound drainage of pancreatic pseudocyst: a prospective comparison with conventional endoscopic drainage. Endoscopy 2006; 38: 355-359
100 Jacobson BC, Baron TH, Adler DG et al. ASGE guideline: The role of endoscopy in the diagnosis and the management of cystic lesions and inflammatory fluid collections of the pancreas. Gastrointest Endosc 2005; $61: 363-370$

101 Vitas GJ, Sarr MG. Selected management of pancreatic pseudocysts: operative versus expectant management. Surgery 1992; 111: 123 130

102 Yeo CJ, Bastidas JA, Lynch-Nyhan A et al. The natural history of pancreatic pseudocysts documented by computed tomography. Surg Gynecol Obstet 1990; 170: 411-417

103 Lerch MM, Stier A, Wahnschaffe U et al. Pancreatic pseudocysts: observation, endoscopic drainage, or resection? Dtsch Arztebl Int 2009; 106: $614-621$

104 Andrén-Sandberg A, Dervenis C. Pancreatic pseudocysts in the 21st century. Part II: natural history. JOP 2004; 5: 64-70

105 Gouyon B, Lévy P, Ruszniewski P et al. Predictive factors in the outcome of pseudocysts complicating alcoholic chronic pancreatitis. Gut 1997; 41: $821-825$

106 Varadarajulu S, Trevino J, Wilcox CM et al. Randomized trial comparing EUS and surgery for pancreatic pseudocyst drainage. Gastrointest Endosc 2010; 71: AB116-AB116

107 Rosso E, Alexakis N, Ghaneh $P$ et al. Pancreatic pseudocyst in chronic pancreatitis: endoscopic and surgical treatment. Dig Surg 2003; 20: 397-406

108 Binmoeller KF, Seifert $H$, Walter $A$ et al. Transpapillary and transmural drainage of pancreatic pseudocysts. Gastrointest Endosc 1995; 42 : $219-224$

109 Varadarajulu S, Christein JD, Tamhane A et al. Prospective randomized trial comparing EUS and EGD for transmural drainage of pancreatic pseudocysts (with videos). Gastrointest Endosc 2008; 68: 1102 1111

110 Beckingham IJ, Krige JE, Bornman PC et al. Endoscopic management of pancreatic pseudocysts. Br J Surg 1997; 84: 1638-1645

111 Funnell IC, Bornman PC, Krige JE et al. Endoscopic drainage of traumatic pancreatic pseudocyst. Br J Surg 1994; 81: 879-881

112 Cremer M, Deviere J, Engelholm L. Endoscopic management of cysts and pseudocysts in chronic pancreatitis: long-term follow-up after 7 years of experience. Gastrointest Endosc 1989; 35: 1-9

113 Arvanitakis M, Delhaye M, Bali MA et al. Pancreatic-fluid collections: a randomized controlled trial regarding stent removal after endoscopic transmural drainage. Gastrointest Endosc 2007; 65: 609-619

114 Balachandra S, Siriwardena AK. Systematic appraisal of the management of the major vascular complications of pancreatitis. Am J Surg 2005; 190: 489-495

115 Delhaye M, Matos C, Devière J. Endoscopic technique for the management of pancreatitis and its complications. Best Pract Res Clin Gastroenterol 2004; 18: 155 - 181

116 Bernades P, Baetz A, Lévy P et al. Splenic and portal venous obstruction in chronic pancreatitis. A prospective longitudinal study of a medical-surgical series of 266 patients. Dig Dis Sci 1992; 37: 340 346

117 Breslin N, Wallace MB. Diagnosis and fine needle aspiration of pancreatic pseudocysts: the role of endoscopic ultrasound. Gastrointest Endosc Clin N Am 2002; 12: 781 - 790 , viii

118 Sriram PV, Kaffes AJ, Rao GV et al. Endoscopic ultrasound-guided drainage of pancreatic pseudocysts complicated by portal hypertension or by intervening vessels. Endoscopy 2005; 37: $231-235$

119 Lawrence C, Howell DA, Stefan AM et al. Disconnected pancreatic tail syndrome: potential for endoscopic therapy and results of long-term follow-up. Gastrointest Endosc 2008; 67: 673-679

120 Varadarajulu S, Noone TC, Tutuian $R$ et al. Predictors of outcome in pancreatic duct disruption managed by endoscopic transpapillary stent placement. Gastrointest Endosc 2005; 61: 568 - 575

121 Devière J, Bueso H, Baize $M$ et al. Complete disruption of the main pancreatic duct: endoscopic management. Gastrointest Endosc 1995; 42: $445-451$

122 Pelaez-Luna M, Vege SS, Petersen BT et al. Disconnected pancreatic duct syndrome in severe acute pancreatitis: clinical and imaging characteristics and outcomes in a cohort of 31 cases. Gastrointest Endosc 2008; 68: 91 - 97

123 Trevino JM, Tevino JM, Tamhane A et al. Successful stenting in ductal disruption favorably impacts treatment outcomes in patients undergoing transmural drainage of peripancreatic fluid collections. J Gastroenterol Hepatol 2010; 25: 526-531 
124 Golzarian J, Nicaise N, Devière J et al. Transcatheter embolization of pseudoaneurysms complicating pancreatitis. Cardiovasc Intervent Radiol 1997; 20: 435 - 440

125 Smits ME, Rauws EA, Tytgat GN et al. The efficacy of endoscopic treatment of pancreatic pseudocysts. Gastrointest Endosc 1995; 42: 202 207

126 Banerjee S, Shen B, Baron TH et al. Antibiotic prophylaxis for GI endoscopy. Gastrointest Endosc 2008; 67: 791 - 798

127 Abdallah AA, Krige JEJ, Bornman PC. Biliary tract obstruction in chronic pancreatitis. HPB (Oxford) 2007; 9: 421-428

128 Sarles $\mathrm{H}$, Sahel J. Cholestasis and lesions of the biliary tract in chronic pancreatitis. Gut 1978; 19: $851-857$

129 Frey CF, Suzuki M, Isaji S. Treatment of chronic pancreatitis complicated by obstruction of the common bile duct or duodenum. World J Surg 1990; 14: 59-69

130 Kahaleh M, Behm B, Clarke BW et al. Temporary placement of covered self-expandable metal stents in benign biliary strictures: a new paradigm? (with video) Gastrointest Endosc 2008; 67: 446 - 454

131 Tabibian J, Asham E, Goldstein L et al. Endoscopic treatment with multiple stents for post-liver-transplantation nonanastomotic biliary strictures. Gastrointest Endosc 2009; 69: 1236-1243

132 Mahajan A, Ho H, Sauer B et al. Temporary placement of fully covered self-expandable metal stents in benign biliary strictures: midterm evaluation (with video). Gastrointest Endosc 2009; 70: 303-309

133 Kahl S, Zimmermann S, Genz I et al. Risk factors for failure of endoscopic stenting of biliary strictures in chronic pancreatitis: a prospective follow-up study. Am J Gastroenterol 2003; 98: 2448 - 2453

134 Catalano MF, Linder JD, George $S$ et al. Treatment of symptomatic distal common bile duct stenosis secondary to chronic pancreatitis: comparison of single vs. multiple simultaneous stents. Gastrointest Endosc 2004; 60: 945 -952

135 Pozsár J, Sahin P, László $F$ et al. Medium-term results of endoscopic treatment of common bile duct strictures in chronic calcifying pancreatitis with increasing numbers of stents. J Clin Gastroenterol 2004; 38: $118-123$

136 Draganov P, Hoffman B, Marsh W et al. Long-term outcome in patients with benign biliary strictures treated endoscopically with multiple stents. Gastrointest Endosc 2002; 55: 680-686

137 Lawrence C, Romagnuolo J, Payne KM et al. Low symptomatic premature stent occlusion of multiple plastic stents for benign biliary strictures: comparing standard and prolonged stent change intervals. Gastrointest Endosc 2010; 72: 558-563

138 Kiehne K, Fölsch UR, Nitsche R. High complication rate of bile duct stents in patients with chronic alcoholic pancreatitis due to noncompliance. Endoscopy 2000; 32: $377-380$

139 Morelli G, Fazel A, Judah J et al. Rapid-sequence endoscopic management of posttransplant anastomotic biliary strictures. Gastrointest Endosc 2008; 67: 879-885

140 Cahen DL, Rauws EA, Gouma DJ et al. Removable fully covered self-expandable metal stents in the treatment of common bile duct strictures due to chronic pancreatitis: a case series. Endoscopy 2008; 40 : $697-700$

141 Siriwardana HPP, Siriwardena AK. Systematic appraisal of the role of metallic endobiliary stents in the treatment of benign bile duct stricture. Ann Surg 2005; 242: 10-19

142 van Boeckel PGA, Vleggaar FP, Siersema PD. Plastic or metal stents for benign extrahepatic biliary strictures: a systematic review. BMC Gastroenterology 2009; 9: 96
143 Cantù P, Hookey LC, Morales A et al. The treatment of patients with symptomatic common bile duct stenosis secondary to chronic pancreatitis using partially covered metal stents: a pilot study. Endoscopy 2005; 37: $735-739$

144 Behm B, Brock A, Clarke BW et al. Partially covered self-expandable metallic stents for benign biliary strictures due to chronic pancreatitis. Endoscopy 2009; 41: 547-551

145 Davids PH, Tanka AK, Rauws EA et al. Benign biliary strictures. Surgery or endoscopy? Ann Surg 1993; 217: 237-243

146 Tocchi A, Mazzoni G, Liotta G et al. Management of benign biliary strictures: biliary enteric anastomosis vs endoscopic stenting. Arch Surg 2000; $135: 153-157$

147 Joergensen $M$, Brusgaard $K$, Crüger DG et al. Incidence, prevalence, etiology, and prognosis of first-time chronic pancreatitis in young patients: a nationwide cohort study. Dig Dis Sci 2010; 55: 2988 - 2998

148 Witt H. Gene mutations in children with chronic pancreatitis. Pancreatology 2001; 1: 432-438

149 Wang W, Liao Z, Li Z-S et al. Chronic pancreatitis in Chinese children: etiology, clinical presentation and imaging diagnosis. J Gastroenterol Hepatol 2009; 24: $1862-1868$

150 Iacopini F, Mutignani M, Perri V et al. Chronic pancreatitis: morphologic differences at disease onset between pediatric and adult patients. Gastroenterology 2010; 138: S-395

151 Hsu RK, Draganov P, Leung JW et al. Therapeutic ERCP in the management of pancreatitis in children. Gastrointest Endosc 2000; 51: 396 400

152 Iqbal CW, Moir CR, Ishitani MB. Management of chronic pancreatitis in the pediatric patient: endoscopic retrograde cholangiopancreatography vs operative therapy. J Pediatr Surg 2009; 44: 139-143 ; discussion 143

153 Li Z-S, Wang W, Liao $Z$ et al. A long-term follow-up study on endoscopic management of children and adolescents with chronic pancreatitis. Am J Gastroenterol 2010; 105: 1884-1892

154 Dumonceau J-M, Hassan C, Riphaus A et al. European Society of Gastrointestinal Endoscopy (ESGE) Guideline Development Policy. Endoscopy 2012; 44: 626-629

155 Deviere J, Devaere S, Baize $M$ et al. Endoscopic biliary drainage in chronic pancreatitis. Gastrointest Endosc 1990; 36: 96-100

156 Barthet M, Bernard JP, Duval JL et al. Biliary stenting in benign biliary stenosis complicating chronic calcifying pancreatitis. Endoscopy 1994; 26: 569-572

157 Smits ME, Rauws EA, van Gulik TM et al. Long-term results of endoscopic stenting and surgical drainage for biliary stricture due to chronic pancreatitis. Br J Surg 1996; 83: 764-768

158 Vitale GC, Reed DN, Nguyen CT et al. Endoscopic treatment of distal bile duct stricture from chronic pancreatitis. Surg Endosc 2000; 14 $227-231$

159 Farnbacher MJ, Rabenstein T, Ell C et al. Is endoscopic drainage of common bile duct stenoses in chronic pancreatitis up-to-date? Am J Gastroenterol 2000; 95: 1466-1471

160 Eickhoff A, Jakobs R, Leonhardt A et al. Endoscopic stenting for common bile duct stenoses in chronic pancreatitis: results and impact on long-term outcome. Eur J Gastroenterol Hepatol 2001; 13: 1161 1167

161 Cahen DL, van Berkel A-MM, Oskam D et al. Long-term results of endoscopic drainage of common bile duct strictures in chronic pancreatitis. Eur J Gastroenterol Hepatol 2005; 17: 103 - 108

\section{Appendix e1 e2 and e3 are available online:}

online content viewable at:

www.thieme-connect.de/ejournals/abstract/endoscopy/

doi/10.1055/s-0032-1309840 